\title{
ESCRITURA Y MATERNIDAD EN UN POEMARIO DE ROSARIO Castellanos*
}

\author{
María Inés Zaldívar Ovalle**
}

\begin{abstract}
Resumen
El presente artículo da cuenta de la compleja relación entre maternidad, escritura y poesía, tomando como objeto de análisis el poemario En la tierra de en medio, de la escritora mexicana Rosario Castellanos. Coherente con la totalidad de su escritura -al igual como lo hace al reescribir el llamado "indigenismo mexicano"- la autora plasma a través de este poemario su particular visión del mundo de los afectos fundamentales, en este caso de la maternidad.
\end{abstract}

Palabras clave: Rosario Castellanos, maternidad, poesía, escritura.

\section{WRITING AND MOTHERHOOD ON A COLLECTION OF POEMS by Rosario Castellanos}

\begin{abstract}
This article provides an overview of the complex relationship between maternity, writing and poetry, taking as its object of analysis the work of Mexican writer Rosario Castellanos, "En la tierra de en medio". Consistent with her previous writings, in the same way she is when re writing "indigenismo mexicano", the author demonstrates, through her poems, her distinctive perspective on fundamental affects, and specifically in this case her views about maternity.
\end{abstract}

Keywords: Rosario Castellanos, motherhood, poetry, writing.

* El presente texto derivó del seminario Poéticas de la maternidad en España e Hispanoamérica: el cuerpo hendido, realizado en la Universidad de Salamanca los días 27 y 28 de febrero de 2012. Ponencia presentada en el Centre de Recherches Latino-Américaines - Archivos, durante el coloquio Les écritures de la confession dans la Péninsule Ibérique et en Amérique Latine, durante la Jornada de Estudios Interuniversitarios Poitiers (CRLA-Archivos) / Paris Ouest-Nanterre La Défense (CRIIA/ GRELPP) MSHS - Université de Poitiers, durante los días 12-13 de diciembre 2013.

** Chilena. Doctora en Literatura de la Rutgers University. Académica de la Pontificia Universidad Católica de Chile. Santiago, Chile.mizaldiv@uc.cl 
En medio de una generación de magníficos escritores mexicanos de mediados del siglo veinte, destaca la nítida voz de Rosario Castellanos (1925-1974). Leer su obra me resulta tan placentero como doloroso. Supone abrirse ante la lucidez de una escritura que interroga, con alguna que otra respuesta tentativ a. Concuerdo con Eduardo Mejía cuando afirma que sus textos ensayísticos dejan tres grandes lecciones: la amabilidad, el rigor y la vocación (10-11). Aparte de lo anterior, quisiera también destacar que toda su escritura me parece de una gran belleza y asombrosamente honesta.

Una de las temáticas fundamentales tratadas por Castellanos, el mundo indígena, ha reescrito la mirada externa y paternalista que tenía la literatura acerca del llamado "indigenismo mexicano". Ella pasó su infancia y adolescencia en Chiapas, luego trabajó en el Instituto Indigenista del lugar, y allí comprendió este mundo no como una otredad folklórica del México occidental. Es por ello que, como dice Eduardo Mejía[1], "Castellanos escribió una saga donde los indios de México son individuos universales al tiempo que componentes de una civilización compleja, rica e injusta"(citado en Obras I: 7). Esta apreciación se corrobora, por ejemplo, con lo que la misma autora responde a una entrevista:

Uno de sus defectos principales reside en considerar el mundo indígena como un mundo exótico en el que los personajes, por ser las víctimas, son poéticos y buenos. Esta simplicidad me causa risa. Los indios son seres humanos absolutamente iguales a los blancos, sólo que colocados en una circunstancia especial y desfavorable. [...] No me parecen misteriosos ni poéticos. Lo que ocurre es que viven en una miseria atroz. Es necesario describir cómo esa miseria ha atrofiado sus mejores cualidades. (Emmanuel Carballo, citado en Obras I: 231[2])

Esa miseria que diezmó a la tribu, es palabra ineludible y certera en sus novelas y en sus cuentos por donde, como dice en "La muerte del tigre", [...] "los años llegaban ceñudos y el hambre andaba suelta, de casa en casa, tocando a todas las puertas con su mano huesuda" (Castellanos, Obras I: 237).

Y no es solamente en el asunto indígena que Rosario Castellanos nada contra la corriente y establece un discurso propio sino también, por ejemplo, en la estructura simple y lineal de su narrativa, tanto en cuentos 
y novelas, carente de experimentos lingüísticos y temporales como estaba en boga a fines de los sesenta. Es paradojal, por otra parte, apreciar que su poesía -aunque comparto el decir de José Emilio Pacheco en el sentido que es la más trágica de la literatura mexicana (Obras II: 8)-, muchas veces se expresa con un humor agudo, irreverente y desconcertante, en especial cuando habla del amor de la pareja, la maternidad o cuando se asume autobiográficamente como hablante lírico: "Yo soy una señora: tratamiento/ arduo de conseguir, en mi caso, y más útil/ para alternar con los demás que un título/ extendido a mi nombre en cualquier academia/ (...) Soy madre de Gabriel: usted ya sabe, ese niño/ que un día se erigirá en juez inapelable/ y que acaso, además, ejerza de verdugo./ Mientras tanto lo amo." (Obras II: 187-188). ${ }^{1}$

Rosario Castellanos reunió variadas aristas en su vida, tanto en lo personal como en lo profesional. Fue hija de padre hacendado y lejano, y de madre clase media que asciende socialmente al casarse, rígida, distante y opresiva. Estas palabras suyas, que pueden leerse en su obra teatral Salomé, son elocuentes: "Mi madre en vez de leche/ me dio el sometimiento" (Obras II: 326)². Sabemos también que fue criada por una nana indígena a quien adoraba; que tuvo solo un hermano que muere cuando eran pequeños (con efectos devastadores pues siempre se sintió culpable de lo sucedido y de no ser ella quien desaparecía del planeta); que tuvo una adolescencia más bien solitaria y triste, y que dedicó su tiempo a la lectura; que más tarde e inesperadamente se convirtió en una esposa que intentó ser aplicada pero, finalmente, fiel a su naturaleza crítica y reflexiva, resulta ser poco convencional. Por último, fue madre de un hijo único, Gabriel.

Por otra parte, fue una profesional brillante que se desempeñó con éxito como investigadora, crítica, profesora, diplomática. Ahora bien, aparte del juicio externo que podamos tener acerca de su presencia en

1 De ahora en adelante, todas las citas que se harán de los poemas provienen de Rosario Castellanos (1998). Obras II Poesía, Teatro y Ensayo. México D.F: Fondo de Cultura Económica.

2 Esta obra fue publicada inicialmente en 1959, en Editorial Jus, Voces nuevas. En un diálogo entre Madre y Salomé, puede leerse:

Salomé:

¿Por qué no huiste?

Madre:

¿A dónde? Mis hermanas

Tienen su propio infierno.

Y fui educada para obedecer

y sufrir en silencio.

Mi madre en vez de leche

Me dio el sometimiento. (Obras II: 326) 
el campo cultural de la época, me interesa precisar cómo ella se aprecia a sí misma. Me atrevo a decir que, tal como puedo percibirlo en Gabriela Mistral3, en Castellanos el quehacer literario fue el eje que la estructuró, le dio un sentido vital profundo y la definió como persona. Su vida giró en torno a lo que podría llamar una pulsión creativa, a la imperiosa necesidad de ser fiel a la palabra. La palabra que se dice, se escucha, se lee $y$, finalmente, se escribe y canaliza a través de diferentes formatos: la novela, el cuento, el ensayo, el teatro, la poesía. La cito: "Para mí la literatura ha sido la espina dorsal. Y puedo decir, sin hipérbole, que gracias a ella he logrado, no solo sobrevivir (lo que es ya una proeza, dadas las muy difíciles circunstancias en que me crié) sino -además-conservar la razón" (Raúl Ortiz y Ortiz, 2009: 20).

Procede, entonces, como una poeta que está en el mero centro del creador de todas sus criaturas, utilizando un arte poética al estilo creacionista que logra que "el verso sea como una llave/ que abra mil puertas" (Huidobro, Archivos[3]: 391), pero precisando que en Castellanos se percibe una diferencia fundamental en relación al poeta-dios-creador de Huidobro. En ella el énfasis no está tanto en el acto de ser el creador de ese mundo de cosas, pues hasta descree de esa posibilidad ("si es que lo que existe ha sido creado"), sino en la mirada acerca de las cosas mismas y su evolución en el tiempo. Y en ese continuo, inevitable y monótono movimiento circular del paso del tiempo, en ese cambio permanente al que llamamos evolución para "maquillar" y darle otra categoría intentando no ver su inexorable rutina, es donde se sitúa la hablante:

Y yo, coronación de siglos, en que el cambio se llama evolución para darle un sentido de perfeccionamiento y espiral y no de anillo simple que se cierra.

Se llama evolución, por el mismo principio utilitario por el que se vendan los ojos a la mula de noria, vuelta y vuelta, para que no se eche a morir de aburrimiento. (193)

3 Esta afirmación puede corroborarse en el texto de mi autoría "Gabriela Mistral y sus "Locas mujeres" del siglo XX", publicado en Taller de letras 38 (2006): 165-180.

4 Recordemos lo que dice el rey burgués al poeta en medio del jardín: "Daréis vueltas a un manubrio. Cerraréis la boca. Haréis sonar una caja de música que toca valses, cuadrillas y galopas, como no prefiráis moriros de hambre. Pieza de música por pedazo de pan" . 
Dentro de este monótono rodar del tiempo alrededor de la noria (como el poeta hambriento de "El rey burgués" de Darío4[4]), pero rodar que tiene la ilusión de fluir con la gracia de un espiral en movimiento, es donde la hablante se posiciona como "la cereza/ puesta sobre la punta del helado". Y desde esa ubicación percibe un problema: "la piedra en el zapato,/ el aire que se agita y me despeina/ y el arañazo del que convalezco":

Es el Mal. Con Mayúscula. Es la prueba patente de que en el Universo algo falló y alguien tiene la culpa: Dios, el diablo, nuestros primeros padres o los últimos. (194)

La conciencia del mal, la gran caída y posterior culpa original persiste en el universo como un "arañazo", como una "piedra en el zapato" que devela el lado oscuro de las cosas. Ese Mal con Mayúscula que se ha colado y que está siempre latente desde el origen hasta nuestros humanos padres, es un enemigo ineludible que se repite y se repite, y al que hay que pagar tributo, aplacar, para mantener el normal fluir del universo:

Mas yo pago el rescate

-con actos de bondad, con sufrimiento-

para que se restaure el equilibrio

y todo continúe, como ahora, girando.

Esta idea, en verdad, me pasma y de esta certidumbre intocable me sustento. (194)

Y la hablante se hace cargo a través de la palabra; ese es el sentido último de su quehacer, asumir esta naturaleza caída que permanece en el tiempo "con actos de bondad, con sufrimiento/ para que se restaure el equilibrio". Actos de bondad y sufrimiento que se materializan a través de la escritura que es lo que ella sabe y puede hacer. Se abre así toda una dimensión ética radical del oficio de escribir que queda pendiente en esta ocasión, pero que no puedo dejar de señalar, al menos.

Para continuar la reflexión, también me parece que se hace necesario definir previamente otros dos asuntos. El primero, acordar que aquí no se hará un análisis psicológico ni conductual de la madre biológica de Gabriel Guerra Castellanos llamada Rosario Castellanos, nacida en el DF México y fallecida en Tel Aviv, situación hipotética, por cierto, pues sabemos que es imposible en poesía -y a mi parecer en cualquier arte-, 
separar vida y obra. Intentar definir, por lo tanto, quién es realmente esta madre de los poemas nos metería en el meollo de un problema teórico insalvable: el de la posibilidad o imposibilidad de la ficcionalización del yo en poesía. Así las cosas, convengamos en que nuestro foco de atención será la madre que se constituye como tal en la hablante de un poemario titulado En la tierra de en medio, que se publica originalmente dentro de la primera edición de Poesía no eres tú en 1972, y bajo un epígrafe de T. S. Eliot: "Human kind/ cannot bear very much reality" (La especie humana/ no puede soportar demasiada realidad).

Lo segundo que quisiera presentar brevemente, es que hablar de una poética de la maternidad supone dar cuenta de una unidad mínima que indefectiblemente es plural, de un eslabón que se liga a otro y, a su vez, este a un tercero. Así, hablar de maternidad supone al menos una tríada: abuela, madre e hijo/a, explicitando que estamos dejando afuera al marido y progenitor. Pero antes de omitir su participación en este texto, ya que nuestro foco de análisis esta vez se desvía de su presencia, me parece necesario dar cuenta de la relación que establece el padre de la creatura dentro del poemario. Desde el segundo poema, "Elegía", pasando por "Accidente", "Ajedrez", "Pequeña crónica", "Desamor", "Ninfomanía" hasta "La nostalgia", el octavo poema de En la tierra de en medio, puede leerse una pequeña historia en "clave de pareja", por decirlo de alguna manera, de amor y desamor de la relación que establece la madre con el padre de ese hijo. Jugando con los títulos de los textos se podría decir que estamos frente a una "elegía" en la que se recuerda con dudosa "nostalgia" una vida común. La historia se inicia con un lamento en el primer verso, pues "[n]unca, como a tu lado, fui de piedra", se continúa con el "Accidente" que significó estar juntos y que se textualiza de la siguiente manera:

Fui inmunizada a tiempo y para siempre

con un beso anacrónico

y la entrega ficticia

-capaz de simular hasta el rechazo-

y por el juramento, que no es más retórico

porque no es más solemne.

No, no temí la pira que me consumiría

sino el cerillo mal prendido y esta

ampolla que entorpece la mano con que escribo. (182) 
Luego vendrán juegos que se juegan en pareja como el "Ajedrez” en el que: " [...] éramos amigos y, a ratos, nos amábamos; / quizá para añadir otro interés / a los muchos que ya nos obligaban/ decidimos jugar juegos de inteligencia", juego que empieza muy limpiamente pues: "Aprendimos las reglas, les juramos respeto/ y empezó la partida", pero que con el correr de los años frente al tablero toma otro cariz: "Henos aquí hace un siglo, sentados, meditando/ encarnizadamente/ cómo dar el zarpazo último que aniquile/ de modo inapelable y, para siempre, al otro" (182).

A continuación la vida de pareja es relatada descarnadamente por la hablante en "Pequeña crónica": "Entre nosotros hubo/ lo que hay entre dos cuando se aman: / sangre del himen roto[5] (183)", para continuar relatando crudamente la aparición del hijo que le arrebata parte de su vida:

La hemorragia mensual o sea en la que un niño

dice que sí, dice que no a la vida.

Y la vena

— mía o de otra ¿qué más da? - en que el tajo

suicida se hundió un poco o lo bastante

como para volverse una esquela mortuoria. (183)

Pero con la conciencia que, además:

Hubo, quizá, también otros humores:

el sudor del trabajo, el del placer,

la secreción verdosa de la cólera,

semen, saliva, lágrimas.

Nada, en fin, que un buen baño no borre. Y me pregunto

con qué voy a escribir, entonces, nuestra historia.

¿Con tinta? ¡Ay! Si la tinta

viene de tan ajenos manantiales. (183)

Y más tarde el "Desamor" de la pareja que es graficado por la hablante cuando percibe que el marido: "Me vio como se mira al través de un cristal / o del aire / o de nada. / / Y entonces supe: yo no estaba allí" (183). Después de la nada, el recuerdo del todo en "Ninfomanía”, “Te tuve entre mis manos: la humanidad entera en una nuez"(184) y, por último, esa nostalgia que más bien se resuelve en un alivio, en la libertad de bailar descalza, sintiéndose joven y sin complejos: 
Si te digo que fui feliz, no es cierto.

No creas lo que yo creo cuando me engaño.

El recuerdo embellece lo que toca:

te quita la jaqueca que tuviste,

el sopor de la siesta lo transfigura en éxtasis

$y$, en cuanto a ese zapato que apretaba

tanto que te impidió bailar el primer baile,

no hubo zapato. Mira: estás descalza, danzas

eternamente ingrávida en el círculo

cerrado de un abrazo.

Danzas sin esa doble barbilla de tu gula,

sin esa arruga artera

que está acechando alrededor de tu ojo. (184)

No quiero cerrar esta historia de amor y desamor de la pareja, sin acudir al último texto de todo el poemario, "Poesía no eres tú", en el cual nuevamente se presenta a la pareja y al hijo, entreverados en una compleja relación. En un inicio: “Nada hay más que nosotros: la pareja,/ los sexos conciliados en un hijo, / las dos cabezas juntas, pero no contemplándose / (para no convertir a nadie en un espejo)/ sino mirando frente a sí, hacia el otro"(198) pero, con el correr del tiempo aparece el otro, el hijo, aquel que se convierte en "nudo en el que se anuda lo que se había roto"(199).

Así las cosas, abuela, madre (padre) e hijo, todos ellos inscritos dentro de los textos del poemario mencionado, conforman una genealogía que crece y se desarrolla a través de la maternidad. Estos habitantes ocupan un territorio y dan con su presencia un sentido particular al título del poemario, pues la maternidad también podría verse como una tierra de en medio, como un lugar de tránsito, un espacio propio pero sin propiedad, al decir de Julia Kristeva 5 .

5 Utilizo esta expresión de Julia Kristeva pues me parece iluminadora, aunque no se refiera específicamente a la situación de la maternidad sino a un espectro mucho más amplio. Kristeva plantea que en la actualidad estamos ante la formación de nuevos códigos que surgen especialmente desde la marginalidad (los disidentes de la moral oficial tales como pueden ser niños, mujeres, homosexuales, y hasta algunas parejas heterosexuales), en los cuales "se perfila un mapa de lo propio sin propiedad". Ver en Historias de amor 1-6. 
Pienso que es dentro de este contexto de autoconciencia del valor y sentido de su escritura, por una parte, y de la vida como un proceso en movimiento por la otra, que podemos hablar de una poética de la maternidad en la obra de Rosario Castellanos. Es por ello que me parece oportuno comentar aquí que, en otro formato de escritura, la voz de Castellanos ya se expresaba con claridad respecto del tema en 1965. En su artículo "Y las madres qué opinan" puede leerse: "Si la tarea de ser madre consume tantas energías, tanto tiempo y tanta capacidad, si es tan absorbente que no se encuentra raro que sea exclusiva, lo menos que podían hacer quienes deliberan en torno al asunto del control de la natalidad, es saber qué opinan de él las madres" ${ }^{\prime}$, afirma. Para ella el tema es candente e importante de discutir sin tabús, pues no puede seguir "asumiéndose como una de las fatalidades con que la Naturaleza nos agobia como si se extendiese hasta allí el campo del dominio del hombre". Por lo mismo se necesitaría "un cuestionamiento acerca de lo que la maternidad significa no como proceso biológico sino como experiencia humana." (Op. Cit). Castellanos escribe la maternidad como una experiencia desde la mujer y no como un mero proceso biológico, porque mirada solo desde una óptica social, ya sea política, económica, religiosa, esta puede convertirse en "un atentado contra la libre determinación individual" e imponerla "a mujeres que la rechazan porque carecen de vocación, que la evitan porque es un estorbo para la forma de vida que eligieron o de la que se alejan como de un peligro para su integridad física."

Para continuar la reflexión, concordemos que aquí no haré un análisis psicológico ni conductual de la autora en tanto madre biológica, situación hipotética, por cierto, pues sabemos que es imposible en poesía -y a mi parecer en cualquier arte-, separar vida y obra. Intentar definir, por lo tanto, quién es realmente esta madre de los poemas nos metería en el meollo de un problema teórico insalvable: el de la posibilidad o imposibilidad de la ficcionalización del yo en poesía. Así las cosas, convengamos en que nuestro foco de atención será la madre que se constituye como tal en la hablante de su poemario titulado En la tierra de en medio, publicado originalmente dentro de la primera edición de Poesía no eres tú en 1972. [6]

6 Ver en Rosario Castellanos (1965). "Y las madres, qué opinan" Control de la natalidad. En Excélsior, 6 de noviembre de 1965. Reproducido en http:/ / www.ensayistas.org/curso3030/textos/ensayo/ madres.htm 
Lo segundo que quisiera establecer, es que hablar de maternidad supone dar cuenta de una unidad mínima que indefectiblemente es plural, pues toda maternidad supone al menos una tríada: una mujer que tiene una madre, y a su vez un hijo que la hace madre. Explicito que en esta ocasión estamos dejando afuera al progenitor. [7]

\section{La madre de la madre, la abuela}

En el territorio que la precede, nos encontramos con una hablante en búsqueda del propio origen, textualizada en la relación que esta tiene de su propia madre. En el poema "Malinche" una voz lírica que de pronto asume la primera persona nos conduce a su nacimiento e infancia:
Arrojada, expulsada
del reino, del palacio y de la entraña tibia
de la que me dio a luz en tálamo legítimo
y que me aborreció porque yo era su igual
en figura y rango
y se contempló en mí y odió su imagen
y destrozó el espejo contra el suelo.

Yo avanzo hacia el destino entre cadenas

y dejo atrás lo que todavía escucho:

los fúnebres rumores con los que se me entierra.

Y la voz de mi madre con lágrimas ¡con lágrimas!

que decreta mi muerte. (Obras II: 185-186)

Es elocuente la connotación. No puede obviarse que poetizar la infancia desde la Malinche es un gesto que identifica la historia del origen de la hablante con un pretexto (casi en espejo) ya codificado como trágico y maldito, y que ha pasado a la historia como uno de los emblemas contradictorios que tanto puede juzgar a esta mujer como traidora o como inocente chivo expiatorio. Más adelante, el devenir de los versos irá confirmando miméticamente la alusión a esa Malinche nacida en la región de Veracruz al sur de México, allá por 1500. Hablamos de esa Malinche que fuese heredera por ser la primogénita, pero vendida o regalada y luego declarada muerta por la madre para favorecer al hermano menor nacido de otro padre, luego a esa niña-mujer que siendo noble se le esclaviza (y que incluso le da un hijo a Cortés, convirtiéndose en Mariana), y que a pesar de estar sometida frente al invasor es poderosa pues es quien

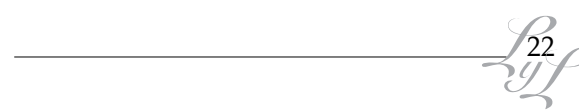


tiene los secretos de la palabra. Se produce entonces un desplazamiento inevitable de la Malinche-Mariana (1500-1527), al origen e infancia de la hablante del poema, tiñendo esta relación madre-hija con una maldición atávica que nos lleva al dolor, la dominación y la traición como marcas de identidad, pero también a la palabra como elemento que tanto salva de la muerte y el sinsentido, como al poder público y privado que supone poseerla.

Luego vendrá la hoja de ruta que la madre entrega a la hija para enfrentar la travesía que le permita llegar a ser lo que tiene que ser; la "Economía doméstica" que corresponde a toda mujer centro y ángel de un buen hogar:

He aquí la regla de oro, el secreto del orden:

tener un sitio para cada cosa

$\mathrm{y}$ tener

cada cosa en su sitio. Así arreglé mi casa.

Impecable anaquel el de los libros:

un apartado para las novelas,

otro para el ensayo

y la poesía en todo lo demás.

Si abres una alacena huele a espliego

Y no confundirás los manteles de lino

Con los que se usan cotidianamente.

Y hay también la vajilla de la gran ocasión

y la otra que se usa, se rompe, se repone

y nunca está completa.

La ropa en su cajón correspondiente

y los muebles guardando las distancias

y la composición que los hace armoniosos.

Naturalmente que la superficie

(de lo que sea) está pulida y limpia.

Y es también natural

que el polvo no se esconda en los rincones. (190) 
La limpieza y el orden de la casa y de las cosas que la componen son el bien supremo. Este esfuerzo doméstico que responde a "la regla de oro" no logra su objetivo. En su defecto, la llave maestra legada por la madre conforma un espacio aséptico, frío, que provoca rechazo y soledad. En términos muy gruesos podemos afirmar que hoy la psiquiatría relaciona la obsesión por la limpieza con la necesidad de limpiar algo que consideramos sucio en nuestro interior. También sabemos que esta obsesión por la limpieza está tipificada dentro de los trastornos obsesivos compulsivos (TOC) como "el síndrome del ama de casa", ya descrito por Freud en 1905, en el caso de Dora, como la patología de la madre de esta, Katharina Gerber:

[...] y así ofrecía el cuadro de lo que puede llamarse la «psicosis del ama de casa». Carente de comprensión para los intereses más vivaces de sus hijos, ocupaba todo el día en hacer limpiar y en mantener limpios la vivienda, los muebles y los utensilios, a extremos que casi imposibilitaban su uso y su goce. No se puede menos que incluir este estado, del cual bastante a menudo se encuentran indicios en las amas de casa normales, en la misma serie que las formas de lavado obsesivo y otras obsesiones de aseo; no obstante, tales mujeres, como sucedía en el caso de la madre de nuestra paciente, ignoran totalmente su propia enfermedad, no la reconocen y, por tanto, falta en ellas un rasgo esencial de la "neurosis obsesiva". (Freud 33)

\section{La madre}

La hija adulta, ya madre, y que no asimiló en su momento el libreto entregado, tampoco logra practicar ahora las lecciones de "Economía doméstica" que le fueron dadas por su progenitora; siempre estará en falta, especialmente en la famosa regla de oro de cada cosa en su lugar:

Algunas cosas. Por ejemplo, un llanto

que no se lloró nunca;

una nostalgia de que me distraje,

un dolor, un dolor del que se borró el nombre,

un juramento no cumplido, un ansia

que se desvaneció como el perfume

de un frasco mal cerrado.

Y retazos de tiempo perdido en cualquier parte. (190-191) 
Esas cosas intangibles, invisibles entre los muebles perfectamente alineados llamadas sentimientos, anhelos, deseos, no encajan en el sistema del orden impuesto; por el contrario, la dueña de casa siempre está y estará en falta al sentir cosas tales como una cierta tristeza que provoca llanto, ansiedad, nostalgia, desasosiego, resultan ser elementos incontrolables que la "desordenan" internamente y le provocan incomodidad y desazón. Por ello la hablante abandona la idea de pretender un orden perfecto $\mathrm{y}$, con agudeza y sentido del humor y para dejar a todos contentos, opta por el mejor doble standar mostrando "a las visitas, / orgullosa, una sala en la que resplandece/ la regla de oro que me dio mi madre" (191).

Luego, ampliando el círculo, vendrán más reglas de comportamiento de "los padres, el maestro, el sacerdote", que la hablante recrimina en los poemas "Lecciones de cosas" y "Post Scriptum". Si para una adecuada conducción de la casa se le enseñó de pequeña que lo primordial eran el orden y la limpieza, en la conducta de la mujer adulta que aspira a ser perfecta, lo altamente deseable serán la postergación, la obediencia y la conformidad. Siempre anteponer a los demás, obedecer sin preguntar, aceptar lo que se venga con resignación y, siempre, siempre perdonar las ofensas y daños poniendo la otra mejilla como lo hacen los buenos, pues finalmente tendrá su recompensa. La hablante intenta cumplir con estos mandatos, y se sienta "a esperar la medalla o el dulce/ y la sonrisa, el premio, por fin, en este mundo" (196). Mas, por el contrario: "[Y] sólo vi desprecio por mi debilidad/ odio por ser el instrumento/ de la maldad ajena" (196). Entonces con lucidez comprende que el camino que debe tomar es otro: formar parte del sistema, con el menor esfuerzo posible, pero haciéndose necesaria: "Hasta que comprendí. Y me hice un tornillo/ bien aceitado con el cual la máquina/ trabaja ya satisfactoriamente" (197). Se hace una pequeña pieza del sistema que gira "en la dirección correcta y a la velocidad/ requerida y con la frecuencia necesaria", preocupándose que le "permitieran seguir cuando me había sido declarada inservible".

Pero vivir la vida no es fácil, incluso para un tornillo. En esas circunstancias requiere de ayudas muy concretas, como la de ese "Valium 10" que permite aliviarse y no perder la perspectiva: 
Y deletreas el nombre del Caos. Y no puedes

dormir si no destapas

el frasco de pastillas y si no tragas una

en la que se condensa,

químicamente pura, la ordenación del mundo. (195)

A fin de cuentas, ¿cómo se ve y se describe esta mujer a sí misma?, básicamente en un constante esfuerzo para ser un "tornillo"-"señora" dentro del sistema, como leemos en "Autorretrato":

yo soy una señora. Gorda o flaca

según las posiciones de los astros,

los ciclos glandulares

y otros fenómenos que no comprendo.

Rubia, si elijo una peluca rubia.

O morena, según la alternativa.

(En realidad, mi pelo encanece, encanece.)

Soy más o menos fea. Eso depende mucho

de la mano que aplica el maquillaje.

Quitada de bulla, como buen tornillo, prefiere evitar eventos sociales para "estar aquí, como ahora, leyendo/ [...], pensando un rato/ en musarañas y otros menesteres"(189),

Escribo. Este poema. Y otros. Y otros.

Hablo desde una cátedra.

Colaboro en revistas de mi especialidad

y un día a la semana publico en un periódico. (188)

\section{El hijo}

Gabriel es el que irrumpe en su existencia convirtiéndola en la madre. No va a legarle una "Economía doméstica", ni tampoco "Lecciones de cosas" para el buen vivir, más bien lo aceptará en su vida con las contradicciones propias que trae su presencia:

Como todos los huéspedes mi hijo me estorbaba

ocupando un lugar que era mi lugar,

existiendo a deshora,

haciéndome partir en dos cada bocado. 
Fea, enferma, aburrida

lo sentía crecer a mis expensas, robarle su color a mi sangre, añadir un peso y un volumen clandestinos a mi modo de estar sobre la tierra.

Su cuerpo me pidió nacer, cederle el paso, darle un sitio en el mundo, la provisión de tiempo necesaria a su historia. ("Se habla de Gabriel"189)

Quisiera, releer los versos anteriores y señalar un aspecto que me parece radical en la relación madre-hijo poetizada en La tierra de en medio. La hablante está consciente de recibir una herencia opresiva que le dificulta fluir con facilidad en la vida, y es dentro de este contexto que se produce la llegada del hijo. Esta nueva situación la dejará hendida, abierta, impidiendo una cicatrización que, metafóricamente, recomponga la casa de caracol que ha construido laboriosamente para aislarse y al mismo tiempo tener un sitio en el mundo. Pero, a pesar de ello, va a seguir construyéndose y reconstruyéndose con esfuerzo, en soledad, a base de tretas íntimas, sentido del humor y, sobre todo, a través del ejercicio de la lectura y la escritura. Logra con ello, no solo un cierto orden, sino una escritura (una huella como la baba del caracol) simple y compleja la vez, pero de una riqueza sorprendente, indesmentible.

Podríamos decir, entonces, que en La tierra de en medio la maternidad es una experiencia paradojal que aunque buscada y consentida, una vez que se materializa, quita. Dice la hablante: "Consentí. Y por la herida en que partió, por esa/ hemorragia de su desprendimiento/ se fue también lo último que tuve/ de soledad, de yo mirando tras de un vidrio. / / Quedé abierta, ofrecida/ a las visitaciones, al viento, a la presencia[8]. (189)" Pero, al mismo tiempo, la madre ofrecida, ofrece, pues es de esa herida desde donde se cuela la palabra (al igual que el hijo) y permite el fluir de esa tinta (o baba de caracol) que en su recorrido va dejando impreso sobre la página el poema.

\section{A modo de cierre}

Considero que en la obra de Rosario Castellanos hay una coherencia, una armonía en la mirada con que percibe, juzga y evalúa el mundo que 
le tocó vivir. Decía al iniciar este trabajo, que Castellanos ha reescrito la mirada acerca del llamado "indigenismo mexicano", pues bien, considero que ha hecho otro tanto con el mundo de los afectos fundamentales. A través del humor coloquial, la ironía y esa honestidad radical que caracteriza su obra, esta se despliega con agudeza e inteligencia, sin piedad, y da cuenta de la complejidad y las contradicciones que constituyen las relaciones afectivas entre los seres humanos. La textualización de la maternidad sigue este mismo camino, pues esta no está exenta de esa piedra en el zapato que todos calzamos. En este caso, la abnegada madre mexicana (y latinoamericana), aquella que se saca el pan de la boca para dárselo al hijo, se confiesa como otro estereotipo con pies de barro. Su escritura la devela como una experiencia compleja, e incluso a veces contradictoria en la medida que puede ser tanto fuente de gozo como de tristeza, de plenitud como de insatisfacción, de búsqueda ansiosa como de cansancio y hasta rechazo, de compañía como de estorbo y, por lo tanto, de auto afirmación como de culpa.

Luego de esta nueva lectura y reflexión de En la tierra de en medio, me parece entender mejor el sentido del título que Rosario Castellanos puso a este conjunto de poemas. Ser madre es habitar en una tierra, en un espacio de germinación terrestre, pero no de cualquier tierra, sino de ese que está en el medio. Ser madre, al igual que la escritura, es exponerse pues es procrear en un espacio del cual no se tiene total posesión ya que, por un lado limita con la tierra de los ancestros y, por el otro, con la de los sucesores, al igual como todo texto escrito viene de otros textos y sigue luego su camino hacia adelante con nuestra herencia pero en solitario. Se está en el espacio de la maternidad y de la escritura sabiendo que de uno y de otro lado se transitará pasando siempre por este centro, por este medio que tanto es puente como abismo. A veces invadiendo y sacando de allí lo necesario para llegar al otro lado, otras disputando la supremacía con posibles habitantes no deseados y, siempre de paso, utilizando esta tierra/ texto como un corredor porque pareciera que, ya germinado y engendrado el fruto, la vida que se quiere no está allí sino en la otra parte.

$Y$, por último, quisiera dejar constancia que recién ahora puedo entender mejor el epígrafe de Eliot que utilizó Rosario Castellanos en este poemario para hablar de la maternidad ("Human kind/ cannot bear very much reality", La especie humana / no puede soportar demasiada realidad), puesto que no siempre los humanos podemos soportarla, a veces es preciso transformarla en poesía. 


\section{Obras citadas}

Carballo, Emmanuel. Protagonistas de la literatura hispanoamericana del siglo XX (Colección Textos de Humanidades, México, UNAM, 1986). México DF: Alfaguara, 2007.

Castellanos, Rosario. Obras I Narrativa. México, D.F: Fondo de Cultura Económica, 1996.

Obras II Poesía, Teatro y Ensayo. México, D.F: Fondo de Cultura Económica, 1998.

"Y las madres, qué opinan". Control de la natalidad. Excélsior

[México] 6 de nov. 1965: s.p. Web 2014. Reproducido en http://www.ensayistas.org/curso3030/textos/ ensayo/madres.htm

Darío, Rubén. "El rey burgués" en Cuentos completos. México: Fondo de Cultura Económica, 1995.

Freud, Sigmund. "Tres ensayos de teoría sexual. Fragmento de análisis de un caso de histeria 1905". Trad. José L. Etcheverry. Ordenamiento, comentarios y notas de James Strachey con la colaboración de Anna Freud, asistidos por Alix Strachey y Alan Tyson. Obras completas Sigmund Freud. Volumen 7 (1901-05). Buenos Aires: Amorrortu editores, 1992.

Huidobro, Vicente. "El espejo de agua (1916)". Vicente Huidobro Obra Poética. España: ALLCA XX Colección Archivos, 2003.

Kristeva, Julia. Historias de amor. Madrid: Siglo Veintiuno Editores, 1991.

Ortiz y Ortiz, Raúl. "La tenaz trayectoria de Rosario Castellano". E-Journal [México, D.F.] 2009: s/p. Web. Reproducido en http://www.ejournal.unam.mx/ uni/029/UNI02905.pdf

Zaldívar, María Inés. "Gabriela Mistral y sus "Locas mujeres" del siglo XX". Taller de letras 38, (2006): 165-180. 